\title{
Guerrilla en Neltume y el surgimiento de una narrativa de resistencia armada en Chile ${ }^{1}$
}

\author{
Cecilia Paz Vera Wilke²
}

\begin{abstract}
Resumen
A partir de la lectura y el análisis discursivo de obras como Guerrilla en Neltume. Una historia de lucha y resistencia en el sur de Chile (2003) del Comité Memoria Neltume y El último. Sumarísima relación de Samuel Huerta Mardones (2004) de Omar Saavedra Santis, es posible advertir dentro de la literatura chilena el surgimiento de una narrativa que expone la experiencia de resistencia armada en el sur del país durante la dictadura, la cual se enmarca dentro de la tradición literaria de los relatos de guerrilla en América Latina, y cuya importancia radica en que permite e incentiva la reflexión y discusión que aún no se ha hecho en cuanto a la experiencia guerrillera en Chile.
\end{abstract}

Palabras clave: Narrativa post dictadura, narrativa de resistencia, lucha armada, guerrilla.

\begin{abstract}
From the reading and discursive analysis of narrative works such as Guerrilla en Neltume. Una historia de lucha y resistencia en el sur de Chile (2003) by Comité Memoria Neltume and El último. Sumarisima relación de Samuel Huerta Mardones (2004) by Omar Saavedra Santis, it is possible to notice the emergence of a sort of narrative within Chilean literature that displays the experience of armed resistance in the south of Chile during the dictatorship. This narrative is part of the Latin American literary tradition of guerrilla narratives and encourages a critical reflection and debate on the Chilean experience of guerrilla.
\end{abstract}

Key words: Post-dictatorship narrative, resistance narrative, armed struggle, guerrilla. 


\begin{abstract}
Resumem
A partir da leitura e o análise discursivo de obras como Guerrilha em Neltume. Uma historia de luta e resistência no sul de Chile (2003) do Comité Memoria Neltume e 0 último. Sumaríssima relação de Samuel Huerta Mardones (2004) de Omar Saavedra Santis, é possivel advertir dentro da literatura chilena o surgimento de uma narrativa que expõe a experiência de resistência armada no sul do país durante a ditadura, a qual se enquadra dentro da tradição literária dos relatos de guerrilha em América Latina, e cuja importância radica em que permite e incentiva a reflexão e discussão que ainda não se tem feito em quanto a experiência guerrilheira em Chile.
\end{abstract}

Palavras chave: Narrativa pós ditadura, narrativa de resistência, luta armada, guerrilha.

A propósito de las múltiples reflexiones que han surgido últimamente con motivo de la conmemoración de los cuarenta años del golpe de Estado, las cuales representan distintas miradas de un acontecimiento que, sin duda, marcó la historia de nuestro país en todo sentido, sería interesante examinar desde el campo literario las diferentes narrativas que abordan estos hechos, considerando no sólo aquellas obras de renombre que fueron escritas post golpe o durante la dictadura ${ }^{3}$, sino también las que se han publicado en democracia, y cuyos mundos representados vienen a completar el imaginario que se ha formado en torno a este periodo, permitiendo así, además, reflexionar sobre nuestro pasado histórico más reciente.

Entre las obras escritas en el último tiempo, post dictadura, se puede observar el surgimiento de una narrativa que, tal vez con la distancia que otorga el tiempo transcurrido, intenta reconstruir la memoria histórica de diferentes sectores políticos, comunidades o actores sociales que fueron protagonistas o testigos de los cambios políticos, sociales, económicos y culturales que se produjeron con el quiebre del Estado de Derecho en 1973, y que antes no habían tenido cabida en los primeros relatos testimoniales o ficcionales

3 La crítica y los estudios literarios han abordado ampliamente la narrativa chilena que se gestó después del golpe militar tanto dentro del país como en el exilio, destacando principalmente las obras testimoniales que denunciaban las violaciones de los Derechos Humanos cometidas en dictadura, como Tejas Verdes (1974) de Hernán Valdés, El estadio (1974) de Sergio Villegas, Prisión en Chile (1975) de Alejandro Witker, Cerco de púas (1977) de Aníbal Quijada, Prigué. Prisionero de Guerra en Chile (1977) de Rolando Carrasco, Un día de octubre en Santiago (1980) de Carmen Castillo, Un viaje por el infierno (1984) de Alberto Gamboa, entre otros. Por otro lado, la narrativa de ficción, denominada por algunos como literatura política, comprometida y/o de resistencia que consta de un mayor valor simbólico para representar la realidad histórica y política del país, como El paso de los gansos (1975) de Fernando Alegría, Soñé que la nieve ardía (1975) y Novios y solitarios (1975) de Antonio Skármeta, Este lugar sagrado (1977) de Poli Délano, Los convidados de piedra (1978) de Jorge Edwards, Pan de pascua (1978) de Carlos Cerda, entre otros. Véase Promis (1996). 
que expresaban lo vivido en aquella época. Según Cristián Montes, en esta narrativa, cuyos representantes son Diamela Eltit, Carlos Franz, Ramón Díaz Eterovic, Germán Marín, entre otros, "se aprecia una problematización del presente, un intento de elaborar el duelo respecto a las muertes acaecidas en la dictadura y una reflexión sobre las vastas consecuencias de la experiencia vivida, de la falta de compromiso con la historia, de la violencia generalizada" (2011: 2), en concomitancia con la necesidad de no olvidar lo sucedido y otorgar una significación a los hechos traumáticos que aún afectan a la sociedad.

Asimismo, se puede advertir que algunas de las obras publicadas durante la última década, independiente del género o modo discursivo que utilicen, han incorporado temáticas que antes sólo habían sido abordadas en forma tangencial o simplemente no se mencionaban en la prosa nacional; hablamos sin ir más lejos, de las violaciones o vejámenes sexuales a mujeres durante la dictadura, tema que si bien ha sido desarrollado tanto en testimonios como en novelas ${ }^{4}$, tal vez no había alcanzado hasta ahora la crueldad y el sadismo que se aprecia, por ejemplo, en Carne de Perra (2009) de Fátima Sime, donde se presenta una relación de poder y dependencia entre víctima y victimario que se plasma en el Síndrome de Estocolmo ${ }^{5}$ que afecta a la protagonista.

Otro tema que tampoco ha sido retratado en profundidad por la literatura chilena, es la lucha armada desarrollada por algunos grupos al interior del país como parte de la resistencia al régimen oficialista ${ }^{6}$, cuyas acciones recién desde la publicación de Guerrilla en Neltume. Una historia de lucha y resistencia en el sur de Chile (2003) del Comité Memoria Neltume, con objeto de la conmemoración del trigésimo aniversario del golpe de Estado, han salido a la luz logrando cierta notoriedad. Posteriormente, surgieron obras como El último. Sumarísima relación de la historia de Samuel Huerta Mardones (2004) de Omar Saavedra Santis y Los fusileros. Crónica secreta

4 Nos referimos, por ejemplo, a los relatos testimoniales Un día de octubre en Santiago (1980) de Carmen Castillo, El infierno (1993) de Luz Arce y Mi verdad. "Más allá del horror, yo acuso" (1993) de Marcia Alejandra Merino, los cuales abordan la tortura física y psicológica que se realizaba a las mujeres detenidas en los centros de tortura y exterminio. En cuanto a la narrativa de ficción, podemos señalar De golpe, Amalia en el umbral (1991) de Ana María del Río y El desierto (2005) de Carlos Franz, donde las protagonistas también sufren la tortura y la violencia sexual a manos de sus captores.

5 En psiquiatría, este síndrome se manifiesta cuando un rehén o persona en cautiverio se identifica inconscientemente con su raptor, estableciendo así una relación de empatía, afectividad y gratitud que puede prolongarse por largo tiempo, incluso una vez terminado el cautiverio. Se trata, en definitiva, de un lazo emocional entre víctima y victimario provocado por el estado de vulnerabilidad e indefensión de la víctima.

6 En términos generales, la narrativa chilena ha obliterado el tema de la lucha armada, o lo ha presentado muy someramente, acotándolo a algunas alusiones o personajes. Tal vez la obra más reconocida en este sentido sea Tengo miedo torero (2001) de Pedro Lemebel, donde se narra el atentado a Pinochet a partir de la incorporación de un personaje revolucionario que está a cargo de su planificación. 
de una guerrilla en Chile (2007) de Cristóbal Peña, con las cuales se va configurando una muestra importante de relatos que narran operaciones paramilitares realizadas por partidos o agrupaciones políticas que luchaban en plena dictadura para desestabilizar el gobierno de facto $^{7}$.

En este sentido, el siguiente estudio abordará una narrativa que da cuenta de la resistencia armada ocurrida en Chile durante el régimen militar, particularmente aquella que recoge la experiencia de focos guerrilleros en el sur del país a comienzos de la década de los ochenta. Para esto, profundizaremos en dos textos que hacen referencia a la instalación de un grupo político-militar en una zona boscosa de Panguipulli, como parte de los objetivos de la llamada "Operación Retorno" gestada por el Movimiento de Izquierda Revolucionaria (MIR) para acelerar el derrocamiento de la dictadura, el cual finalmente fue detectado por las fuerzas de contrainsurgencia del régimen, siendo sus miembros perseguidos y asesinados en la precordillera austral. Se trata del testimonio Guerrilla en Neltume. Una historia de lucha y resistencia en el sur de Chile (2003), escrito por el Comité Memoria Neltume, agrupación que ha intentado reconstruir la memoria histórica de una zona de trabajadores forestales muy golpeada por la represión militar durante los años de dictadura, y la novela Sumarísima relación de la historia de Samuel Huerta Mardones (2004) de Omar Saavedra Santis, que hace referencia a este mismo hecho real desde la mirada reflexiva y simbólica que entrega la ficción.

\section{Guerrilla en Neltume: de la experiencia a la narración}

Antes de esbozar los aspectos más relevantes de esta narrativa es necesario señalar algunas precisiones históricas sobre la existencia de grupos armados en Chile y el desarrollo de guerrillas ${ }^{8}$. Al respecto, podemos indicar

7 Durante la dictadura existieron al menos tres grupos políticos organizados y reconocidos que tomaron la lucha armada como parte de la resistencia y la rebelión popular impulsada para derrotar a Pinochet, sobre todo a partir de la década de los ochenta, época en que se intensificaron las protestas callejeras y la desaprobación internacional del régimen oficialista. Ellos son: el Movimiento de Izquierda Revolucionaria (MIR), el Frente Patriótico Manuel Rodríguez (FPMR) y el MAPU Lautaro, con las Fuerzas Rebeldes y Populares Lautaro. Véase Historia del MIR. Si quieren guerra, guerra tendrán (2003) de Cristián Pérez, Movimiento de Izquierda Revolucionaria (2012) de Igor Goicovic, De la rebelión popular a la subversión imaginada. Antecedentes de la historia política y militar del Partido Comunista de Chile y del FPMR 1973-1990 (2011) de Luis Rojas, y Jóvenes, rebeldes y armados. Teoría, identidad y praxis del MAPU Lautaro (2007) de Héctor Órdenes.

8 El término guerrilla, que en estricto rigor significa "guerra pequeña", designó inicialmente a "los combates de tipo militar no regular que han acompañado a las actividades de los partisanos en guerras civiles, guerras revolucionarias, y en la resistencia popular a la invasión y la ocupación extranjera" (Osanka, 1975: 296). Sin embargo, con los tiempos modernos el vocablo adquirió un sentido político, además del táctico-militar, con el cual se incorporó un sustento ideológico y revolucionario a la guerrilla, en la medida en que ésta tiene como 
que efectivamente operaron durante la dictadura algunos grupos armados con fines políticos, como el Movimiento de Izquierda Revolucionaria (MIR), partido fundado en 1965 en plena ebullición del proceso revolucionario latinoamericano, que luego de la persecución y represión post golpe se reorganizó, elaborando nuevas estrategias de resistencia para construir una fuerza social, política y militar capaz de terminar con el régimen dictatorial; el Frente Patriótico Manuel Rodríguez (FPMR), creado en 1983, como brazo armado del Partido Comunista, cuyas acciones más importantes fueron la internación de armas en Carrizal Bajo, algunos secuestros y asaltos a retenes, el atentado contra Pinochet, entre otros; y el MAPU Lautaro, escisión del Movimiento de Acción Popular Unitaria, que entre 1981 y 1983 comienza con acciones menores de subversión política y las llamadas "recuperaciones", asaltos a zapaterías y camiones de abastecimiento con el objetivo de entregar los productos a las poblaciones más vulnerables. Sin embargo, en 1988 la organización se vuelca hacia las armas, constituyendo las Fuerzas Rebeldes y Populares Lautaro, que al igual que el FPMR continuaron realizando operaciones paramilitares durante la democracia.

De estos grupos, el MIR fue el primero en desarrollar acciones de resistencia en pleno periodo de represión. Para ello, en 1977 elaboró en el extranjero un proyecto denominado "Plan 78", también conocido como "Operación Retorno", cuyo objetivo central era la reestructuración del partido reingresando cuadros político-militares para iniciar la lucha contra la dictadura. Este plan estipulaba la apertura de dos frentes guerrilleros estables en el sur de Chile, específicamente en Neltume y Nahuelbuta, "Ios que deberían contar con capacidad de combate y significativos apoyos entre la población de las áreas elegidas" (Pérez, 2003: 24). Para Patricio Rivas, ex dirigente mirista, el sentido de una guerrilla rural obedecía a

"[la necesidad] de contar con una zona que permitiera la construcción de una fuerza que vitalizara las luchas sociales y políticas. También apuntaba al viejo anhelo de disponer de una fuerza militar propia. Sin embargo, no era una copia del modelo cubano ni del sandinista. Esta fuerza de alcance social y político debía desplazarse en el campo y la ciudad para producir y acelerar una crisis y abrir paso a una situación de ofensiva, que culminara en un gobierno de amplio espectro o en una situación revolucionaria" (2007: 192-193).

objetivo "alterar o cambiar por completo la estructura social y política de una nación" (Loc. Cit). Para esto debe, por un lado, debilitar al ejército regular, que es la fuerza del poder central, a través de hostigamientos, sabotajes, emboscadas, etc., y por otro, aumentar sus filas con la instrucción y el apoyo de la población, de manera de formar un ejército revolucionario que finalmente pueda vencer al poder gobernante. También hay que considerar que existen distintos tipos de guerrilla: urbana, suburbana y rural. 
Desde esta perspectiva, las palabras de Rivas evidencian un hecho significativo, los focos guerrilleros que el MIR intentó establecer en el sur del país no se transformarían en la clásica guerrilla rural que conocemos a través de las gestas del Che Guevara en Cuba y Bolivia, y la cual predominó en América Latina y el Caribe, como parte de las experiencias revolucionarias que se desencadenaron, principalmente, durante la segunda mitad del siglo $X X^{9}$, pues tanto en el frente de Neltume como en el de Nahuelbuta sólo se pudo desarrollar la primera parte de la lucha guerrillera ${ }^{10}$, que corresponde a la fase de implementación de un destacamento paramilitar en una zona rural de difícil acceso (Vera, 2013: 30), para asegurar, en primer lugar, la sobrevivencia de éste, y luego sentar las bases de un trabajo político con la población.

En efecto, el grupo de Neltume, bautizado como Destacamento Guerrillero Toqui Lautaro y conformado por doce combatientes, se instaló en la precordillera de Valdivia a mediados de 1980. Durante un año aproximadamente realizaron tareas propias de un campamento guerrillero, como el reconocimiento del terreno, la elaboración de mapas, la construcción de tatús y refugios subterráneos, el abastecimiento de comida, etc., sin embargo, no ejecutaron ninguna acción ofensiva ni establecieron relaciones de colaboración con los lugareños ${ }^{11}$, dos conceptos que son determinantes para el éxito de una guerrilla. Además, tuvieron problemas con las redes de contacto y la logística del partido en Santiago. De esta manera, los militares descubrieron el campamento el 27 de junio de 1981, dando paso a una prolongada y fuerte represión que sólo terminaría con la muerte de casi todos los miembros del destacamento en noviembre del mismo año ${ }^{12}$. Por otro lado, en el frente de Nahuelbuta, una vez que se conoce la detección del campamento de Neltume y la posterior persecución de sus combatientes, el jefe de destacamento determinó mantener recluidos a sus hombres en un tatú por meses hasta realizar el repliegue al llano, el cual se desarrolló satisfactoriamente, aunque esto significara el fracaso de las fuerzas políticomilitares en la zona austral.

No obstante, pese al hermetismo y al desconocimiento general que hay respecto a este asunto a nivel nacional, los acontecimientos que ocurrieron en Neltume y Nahuelbuta, revelan que en Chile existió un proyecto concreto de guerrilla, dirigido por el MIR dentro de la lucha revolucionaria popular,

9 Véase Las guerrillas contemporáneas en América Latina (2007) de Alberto Prieto.

10 Véase La guerra de guerrillas (2006) de Ernesto Guevara.

11 Véase Síntesis y evaluación de la experiencia guerrillera de Neltume y Nahuelbuta 19801981 (1985), documento elaborado por los militantes del MIR que participaron en forma directa en la implementación de los focos guerrilleros del sur de Chile.

12 Véase Neltume en Informe de la Comisión Nacional de Verdad y Reconciliación (1991), Tomo II, Vol. I, p. 631-633 (Reedición 1996). 
la cual instaba a la resistencia armada como una de las vías para combatir la dictadura. Teniendo claros estos antecedentes, desde el ámbito literario, podemos señalar que la experiencia guerrillera, o más bien el intento de una guerrilla rural en el sur del país, motivó una narrativa, hasta ahora nunca vista, que expone la resistencia armada de esos años en forma explícita, como es el caso de Guerrilla en Neltume; o en forma implícita, con un menor grado de referencialidad, como ocurre en la novela El último, y que se enmarca dentro de la tradición de los relatos de guerrilla desarrollada vastamente en América Latina y el Caribe.

\section{Aproximación a una narrativa de resistencia armada}

Guerrilla en Neltume es un valioso testimonio colectivo sobre la guerrilla rural que el MIR quiso implantar en el sur del país a comienzos de los ochenta. Su autor intelectual, el Comité Memoria Neltume, reunió para su redacción a algunos de los protagonistas que participaron directamente tanto en la preparación del proyecto guerrillero como en el desarrollo de éste, los cuales integraron el destacamento Toqui Lautaro en algún momento de la historia. Así, a partir de diferentes voces narrativas se va reconstruyendo la experiencia guerrillera en Chile, apoyada además por publicaciones de prensa y material gráfico que proporcionan al relato el carácter documental y la veracidad que requiere el testimonio para validarse como tal. Asimismo, también se presentan relatos enmarcados de algunos militares que participaron en las operaciones de contrainsurgencia en la montaña, los cuales complementan el sentido de la historia y enriquecen la estructura fragmentaria de la obra testimonial.

Por otra parte, aunque Guerrilla en Neltume se centra en la historia de los guerrilleros que se establecieron en la montaña durante los años 1980 y 1981, también podemos decir que rescata la memoria histórica de la zona de Panguipulli y Neltume, denunciando los abusos y las injusticias sociales que han afectado a la población campesina y a las comunidades mapuches desde mucho antes:

"A comienzos de 1900 llega el ferrocarril a Panguipulli y con él la empresa Camino Lacoste y la Compañía Ganadera San Martín, con su vapor O'Higgins, penetran la zona de montaña y se apropian de lagos, ríos y tierra hasta el sector de Fuy. Hay engaños, abusos, despojos y matanzas perdidas e ignoradas por la historia" (Comité Memoria Neltume, 2003: 29).

Pero sobre todo, destaca como antecedente de la resistencia armada de los ochenta, aquella que se produjo después del golpe de Estado en la misma zona, cuando un grupo de trabajadores intentara defender el gobierno de 
la Unidad Popular, bajo el liderazgo de José Gregorio Liendo Vera, conocido como el comandante Pepe ${ }^{13}$ :

"El Chile ya en tinieblas no lo supo, pero durante tres meses un puñado de hombres luchó, combatió y resistió en las montañas de Valdivia, hasta que en diciembre de ese año, diezmados y agotados por la lucha perdida, desalentados por la evidente nula resistencia armada en el resto del país, optan por replegarse hacia las ciudades del Ilano chileno y argentino" (Comité Memoria Neltume, 2003: 35).

En definitiva, el texto de Neltume cumple varias expectativas del testimonio. Como primer punto, pretende anclar en el presente lo que es amenazado por el olvido, dando a conocer realidades que ya no existen (Klein, 2008: 185), y del mismo modo, narrar una acción o conducta ejemplar que conmueva al lector e incentive su reflexión. Cabe señalar, sin embargo, que el propósito de Guerrilla en Neltume no es mostrar a los protagonistas de la guerrilla rural como víctimas de violaciones a los Derechos Humanos, aunque en efecto sí lo son, sino como actores sociales comprometidos con un sueño, con un ideal revolucionario, que finalmente no se pudo concretar.

En este sentido, enfatizar la condición de luchadores sociales por sobre la condición de víctimas, instaura un nuevo paradigma en los relatos de dictadura, pues como señala Bufano (2007) en relación a la narrativa argentina sobre dictadura y acciones de resistencia, quedarse solamente con el papel de víctima sitúa a los protagonistas en un rol pasivo, sin conciencia crítica, restándoles la responsabilidad, el valor y la significación de sus luchas. En Guerrilla en Neltume los ex combatientes del MIR asumen con una mirada analítica su participación en el proyecto guerrillero, configurando una voz colectiva desde la militancia política.

Por su parte, la novela El último escrita por Omar Saavedra, nos proporciona una sorprendente y conmovedora historia basada en la experiencia de guerrilla en Chile. Para ello, el autor incorpora a la anécdota guerrillera distintos elementos narrativos pertenecientes al género de ficción, para construir un mundo diegético verosímil y lleno de simbolismo.

De esta forma, el narrador nos sitúa veinte años después de ocurridos los hechos de resistencia armada en la montaña, cuando "aquel lejano y pequeño país" se encontraba en su mejor momento de crecimiento económico y ya había dejado atrás los tiempos de revolución y luchas contra la dictadura.

13 Véase Chile: Recuerdos de la guerra. Valdivia-Neltume-Chihuío-Liquiñe (s/f) de Comité de Defensa de los Derechos del Pueblo (CODEPU) y Crimen sin castigo: Valdivia, Neltume, Santiago, Tejas Verdes (2004) de Juan Carlos García. También el documental audiovisual La guerra preventiva (1996) de Agnes Denis y Paco Peña. 
Por eso, la aparición del último guerrillero, Samuel Huerta Mardones, quien había permanecido oculto en una zona boscosa de la precordillera, durante todo este tiempo, vino a remover viejas rencillas políticas del pasado. A partir de los recuerdos de Samuel, o Pequén, como le decían sus compañeros, comienza, entonces, la reconstrucción de la experiencia guerrillera desde sus inicios, la cual remite al Destacamento Guerrillero Toqui Lautaro, incluso en los más finos detalles, aunque el narrador no lo señale en forma explícita.

No obstante, como indicamos anteriormente, al ser una obra de ficción, El último, modifica en algunos aspectos la experiencia guerrillera que se desarrolló en el sur de Chile, introduciendo "nuevas situaciones, hechos y personajes imaginarios, como asimismo intertextos literarios que enriquecen el discurso de la novela, como Canto General de Neruda y El Ingenioso Hidalgo Don Quijote de la Mancha de Cervantes (Vera, 2013: 48). Estas referencias literarias tienen directa relación con la guerrilla, pues son obras que pertenecen a la biblioteca del destacamento y las cuales van a adquirir gran relevancia en el relato. Don Pablo y Don Quijote, finalmente se convertirán en personajes en la larga espera de Pequén, quienes en su imaginación le enseñarán que su lucha, y la de todos sus compañeros ya muertos, no fue en vano y, por tanto, es digna de ser narrada como una gesta heroica.

También es interesante en la novela, el contraste entre el pasado y el presente de los protagonistas, pues el discurso revolucionario de antaño, personificado en la figura de Pequén, ya no tiene cabida en una sociedad moderna y neoliberal. Asimismo, se cuestiona el hecho de que algunos de los compañeros que idearon el proyecto guerrillero olvidaran la revolución tan pronto llegara la democracia, como se puede apreciar en el personaje de Roberto Niño, gestor político de la guerrilla y Ministro de Estado en el momento en que Pequén aparece. En suma, El último, no sólo expone una crítica acerca de las razones del fracaso de la guerrilla chilena, sino que aborda más bien el fracaso del proyecto revolucionario en general, cuestionando o desmitificando el imaginario que hay en torno a la revolución y la lucha guerrillera.

Hasta ahora hemos señalado que tanto Guerrilla en Neltume como El último constituyen una muestra representativa de obras que hacen referencia a los movimientos de resistencia armada o de acción guerrillera ${ }^{14}$ que se formaron en Chile para derrocar el régimen de Pinochet. Ambos relatos, por consiguiente, pertenecen a la tradición latinoamericana de los relatos de guerrilla, es decir, corresponden a narraciones sobre insurrección armada,

14 Se entiende por acción guerrillera la ejercida como parte de un proyecto político-militar con un sustento ideológico, y cuyo objetivo es cambiar el régimen social y político imperante de una nación (Vera, 2013: 32). 
generalmente desarrollada en un espacio rural, donde un grupo lucha contra un poder central para alcanzar la liberación y/o revolución del pueblo.

De acuerdo a esta tradición literaria, desarrollada ampliamente en América Latina desde el triunfo de la Revolución Cubana ${ }^{15}$, una narrativa de temática guerrillera plasma la suerte histórica de un plan de acción que tiene como fin transformar una realidad social, desde que se inicia hasta que vence o fracasa (Duchesne, 1992: 82). Desde esta perspectiva, las obras chilenas pertenecen a dicha tradición porque independiente de si el grupo armado cumple o no sus objetivos, se narra el proyecto de la guerrilla desde su planificación hasta su término o desenlace.

En este punto es importante señalar que hasta ahora se consideraba que la literatura chilena no aportaba ningún texto de este tipo al corpus de la literatura latinoamericana ${ }^{16}$, pero con la aparición de textos como Guerrilla en Neltume y El último se hace evidente el vínculo entre éstos y las narraciones de acción guerrillera de América Latina, pues se observan rasgos comunes tanto en su temática como en sus modos de representación. Estos rasgos distintivos son básicamente seis: la referencialidad, el discurso ideológico de la revolución, el efecto de oralidad, el estilo, la trama con temas, motivos y personajes recurrentes, y lo épico ${ }^{17}$.

El surgimiento de esta nueva narrativa, que hemos denominado de resistencia armada o acción guerrillera, representa un avance en la escritura de textos post dictadura, en tanto se aborda una problemática que, por su sustento ideológico, ha permanecido marginada tanto en la opinión pública como en los textos literarios. Sin embargo, el fracaso de la experiencia guerrillera en Chile hace particularmente que nuestra narrativa de resistencia armada posea un pensamiento crítico sobre la significación de

15 A partir de las diferentes guerrillas que se desarrollaron en América Latina durante la segunda mitad del siglo XX, en consonancia con los movimientos de liberación nacional y las luchas antidictatoriales de la época, surgió una tradición literaria de temática guerrillera, cuyos máximos exponentes en un inicio fueron Ernesto Guevara con Pasajes de la guerra revolucionaria (1963) y Diario de Bolivia (1968), Mario Payeras con Los días de la selva (1981) y Omar Cabezas con La montaña es algo más que una inmensa estepa verde (1982).

16 En La guerrilla en la literatura hispanoamericana. Aporte bibliográfico (1996) de Lancelot Cowie, sólo se menciona a La insurrección (1982) de Antonio Skármeta como la única obra de literatura chilena que aborda la guerrilla, sin embargo, hay que decir que esta novela expone la insurrección de un pueblo nicaragüense en el contexto de la guerra revolucionaria del Frente Sandinista de Liberación Nacional (FSLN) y, por tanto, no recoge experiencias de guerrilla chilena. Por otro lado, la academia y la crítica literaria, en todos estos años, no se ha interesado en las obras que hemos seleccionado para este estudio, ni se ha establecido el vínculo que tienen con la tradición de relatos de guerrilla de América Latina.

17 Véase Hacia una narrativa de acción guerrillera en Chile (2013) de Cecilia Vera Wilke. Tesis para optar al grado de Magíster en Literatura Latinoamericana y Chilena, Universidad de Santiago de Chile. 
esa experiencia. En otras palabras, el hecho de que se haya fracasado en el intento revolucionario permite que estos textos no sólo muestren la historia o anécdota guerrillera, como ocurre en algunos relatos de guerrilla, sino que presenten claras reflexiones sobre las responsabilidades políticas y sociales que caben en dicha derrota.

El testimonio de Neltume, por ejemplo, además de relatar la historia de los miristas que decidieron volver al país para insertarse en plena Cordillera de los Andes para luchar contra la dictadura, realiza un análisis descarnado al proyecto guerrillero, pero no cuestionando sus motivaciones o su razón de ser: "El plan específico de abrir frentes guerrilleros en un futuro mediato en el sur, era la continuidad, consecuencia lógica y desarrollo natural del enfrentamiento antidictadura en el marco de la guerra popular" (Comité Memoria Neltume, 2003: 59), si no su planificación y concreción. Las principales críticas apuntan hacia la dirección del partido y a los responsables del proyecto, quienes en forma tozuda creían que la realidad de nuestras montañas se podía comparar a la Sierra Maestra. No obstante, también existe una autocrítica de los propios participantes, quienes intentan esclarecer los motivos por los que fueron detectados: la captura de dos compañeros cuando se inició el proyecto, los reiterados encuentros con campesinos, el relajo en las medidas de seguridad producto del atraso de algunas tareas, entre otros.

Asimismo, entre las múltiples reflexiones que hacen los protagonistas, se destaca el valor de los combatientes, quienes subsistieron durante meses en las peores condiciones que podríamos imaginar, en pleno invierno, sin la ropa adecuada, sin comida, enfermos, cercados por el enemigo, etc., con lo cual se enaltece la convicción y el compromiso de esos hombres, presentándolos, como dijimos anteriormente, como luchadores sociales:

Cualquiera podrá estar de acuerdo, o no, con la utopía socialista que aquellos revolucionarios del MIR pretendían para su pueblo; también con los planes y métodos - llamémosle también ideas y estrategiacon que aquella organización revolucionaria pretendió derrocar a la dictadura militar; cualquiera podrá estar o no de acuerdo con las definiciones y objetivos de aquel Plan 78, y es natural que así sea. Pero a la luz de la historia, nadie puede desconocer ni dejar de rendirse ante la nobleza del esfuerzo y del sacrificio de ese puñado de chilenos. Ellos pusieron la voluntad revolucionaria que hacía falta para abordar tareas en las que se necesitaba algo más que una actitud militante (Comité Memoria Neltume, 2003: 289).

De este modo, se reconoce la conducta ejemplar de aquellos hombres, tan patente en el género testimonial, y se intenta reconstruir la verdad que ha sido silenciada durante años. Recordemos que uno de los objetivos del testimonio es dar a conocer una realidad que generalmente ha sido oculta 
o tergiversada por la historia oficial, de manera de levantar la voz de los oprimidos y reconstruir la verdad del otro desde los mismos protagonistas, otorgando, por cierto, el valor que tiene para toda una comunidad. Desde esta mirada, Paulo Slachevsky es claro al precisar la relevancia de un texto como Guerrilla en Neltume en la actualidad, pues rescata del olvido una de las tantas manifestaciones de resistencia que hubo en dictadura:

Se teme conocer y reconocer estos fragmentos de historia, se teme enfrentarse a todo lo que significó esta decisión de lucha. Nuestra sociedad, nosotros mismos, los que aquí estamos, por inacción u omisión, muchas veces olvidamos que el advenimiento de la apertura democrática se lo debemos a cada una de estas manifestaciones, se lo debemos también a cada hombre y mujer que resistió a la dictadura, a cada resistente muerto, a cada resistente sobreviviente (2003: párrafo 2).

La obra de Saavedra, en tanto, cuestiona básicamente el proyecto revolucionario desde distintos puntos de vista. En primer lugar, el solo hecho de insertar al último guerrillero a comienzos del siglo XXI permite ver cómo el discurso revolucionario se fue diluyendo en el tiempo hasta desaparecer: "(...) había sido encontrado un curioso ejemplar vivo de una especie que se creía extinguida para siempre (...) un guerrillero que se ocultaba desde hacía más de veintidós años en la espesura de la selva fría" (Saavedra, 2004: 12). En este sentido, la experiencia guerrillera aparece en El último como una reminiscencia, como un recuerdo remoto de una realidad de la que ya nadie se acuerda. Por tanto, se advierte una crítica al olvido y a la indiferencia de una sociedad moderna que vive en un mundo superficial, donde lo único importante es lo económico. Por esto, Pequén, desilusionado de la vida que le presentaron, decide volver a la montaña y abandonar para siempre "la civilización".

Es interesante, además, la paradoja de que el último guerrillero haya sido precisamente Pequén, uno de los peores miembros del destacamento: torpe, temeroso, sin convicción ideológica, poco instruido, etc. Lo que viene a desmitificar la idealizada moral guerrillera y el imaginario del hombre nuevo que es vinculado a todos los combatientes.

Asimismo, se evidencia la mencionada "madurez política" de algunos personajes, como Roberto Niño, que de ser jefe político de la guerrilla durante la dictadura, termina siendo Ministro Secretario General de Gobierno en un régimen democrático, olvidando la ideología marxista-leninista. En varios pasajes de la novela se reflexiona acerca del rumbo que tomó la sociedad en términos políticos y económicos:

¿Qué se hizo del PCUS? ¿Los países socialistas, qué se hicieron? ¿Qué se hizo aquel luchar de patricios y plebeyos? ¿De la lucha de clases? La 
dialéctica de la vida era severa en castigar a los que se empecinaban en la adoración de cadáveres exquisitos. La llamada revolución socialista era uno de esos cadáveres. Ahora, una verdadera revolución social ya no era la obra de masas anónimas y brutas dirigidas por vanguardias mesiánicas, sino la suma de esfuerzos individuales de sujetos reales y contemporáneos movidos por el deseo de mejorar sus propias condiciones de vida con sus propias manos (Saavedra, 2004: 166).

Al respecto, es un gran acierto de la novela presentar la realidad del país veinte años después de la experiencia guerrillera, pues en la mayoría de los relatos de este tipo, pareciera que el discurso de la revolución quedara congelado en la historia, como la utopía que no pudo ser, o bien como el gran triunfo de un movimiento de masas, pero muy pocos textos exhiben qué sucedió después de esa revolución. ¿Qué pasó con los partidos, con sus militantes, con los ideales? (Vera, 2013: 89). Situación que, sin duda, incentiva la discusión acerca del devenir histórico del país.

\section{Para concluir}

En definitiva, las obras que hemos seleccionado constituyen una muestra de la nueva narrativa post dictadura que ha surgido lentamente en los últimos años, y la cual retrata la acción o resistencia armada ocurrida en la época de dictadura. La relevancia de esta narrativa es que, además de contribuir al corpus de la literatura de guerrilla desarrollada en América Latina, profundiza especialmente en la derrota del proyecto guerrillero en Chile, promoviendo un pensamiento crítico acerca de los procesos políticos, sociales y económicos vividos en el país.

\section{Referencias bibliográficas}

\section{Fuentes primarias}

COMITÉ MEMORIA NELTUME (2003). Guerrilla en Neltume. Una historia de lucha y resistencia en el sur de Chile. Santiago de Chile: LOM Ediciones.

SAAVEDRA, O. (2004). El último. Sumarísima relación de la historia de Samuel Huerta Mardones. Concepción: Escaparate Ediciones.

\section{Fuentes secundarias}

ARCE, L. (1993). El infierno. Santiago de Chile: Planeta.

BUFANO, S. (2007). La guerrilla argentina. El final de una épica impura. Revista 
Lucha Armada (Ejercitar la Memoria Editores), Año 3, № 8. Disponible en http:// so000260.ferozo.com/pdf/lucharmada8.pdf

CASTILLO, C. (1986). Un día de octubre en Santiago. Santiago de Chile: Terranova. CODEPU (s/f). Chile: Recuerdos de la guerra. Valdivia-Neltume-Chihuío-Liquiñe. Colección Verdad y Justicia, Vol. II.

COMISIÓN NACIONAL DE VERDAD Y RECONCILIACIÓN (1991). Neltume, Informe de la Comisión Nacional de Verdad y Reconciliación (Informe Rettig), Tomo II, Vol. I, p. 631-633, (reedición 1996).

COWIE, L. (1996). La guerrilla en la literatura hispanoamericana. Aporte bibliográfico. Caracas: Universidad Simón Bolívar.

DENIS, A. y PEÑA, P. (Directores) (1996). La guerra preventiva, DVD.

DUCHESNE, J. (1992). Narraciones guerrilleras: configuración de un sujeto épico de nuevo tipo en Narraciones de testimonio en América Latina: cinco estudios. Puerto Rico: Editorial de la Universidad de Puerto Rico, pp. 81-151.

FRANZ, C. (2005). El desierto. Santiago de Chile: Sudamericana.

GARCÍA, J. (2004). Crimen sin castigo. Valdivia, Neltume, Santiago, Tejas Verdes. Santiago de Chile: Mosquito Comunicaciones.

GOICOVIC, I. (2012). Movimiento de Izquierda Revolucionaria. Concepción: Escaparate Ediciones.

GUEVARA, E. (2006). La Guerra de Guerrillas (1960). Bogotá: Ocean Sur.

KLEIN, I. (2008). La ficción de la memoria: la narración de historias de vida. Buenos Aires: Prometeo Libros.

LEMEBEL, P. (2010). Tengo miedo torero. Santiago de Chile: Editorial Planeta.

LOM Ediciones (2003). Si no fuera por los soñadores. Presentación de libro sobre experiencia de Neltume. Acto en Sala América de la Biblioteca Nacional. Disponible en internet: http://www.archivochile.com/Memorial/caidos_mir/G/ guzman_soto_prospero.pdf

MERINO, M. (1993). Mi verdad. "Más allá del horror, yo acuso". Santiago de Chile: s.e.

MONTES, C. (2011). Carne de perra de Fátima Sime: la persistencia de lo urgente. Iberoamericana XI, № 44, pp. 63-78.

ÓRDENES, H. (2007). Jóvenes, rebeldes y armados. Teoría, identidad y praxis del MAPU Lautaro. Santiago de Chile: Tesis para optar al grado de Licenciado en Historia, Universidad de Chile. 
OSANKA, F. (1975). Guerras intestinas: Guerra de guerrillas en Enciclopedia Internacional de las Ciencias Sociales, Vol. V. Madrid: Aguilar.

PEÑA, J. (2012). Los fusileros. Crónica secreta de una guerrilla en Chile. Santiago de Chile: Random House Mondadori.

PÉREZ, C. (2003). Historia del MIR. Si quieren guerra, guerra tendrán. Estudios Públicos, No 91, pp. 5-44.

PRIETO, A. (2007). Las guerrillas contemporáneas en América Latina. Bogotá: Ocean Sur.

PROMIS, J. (Editor) (1996). 1973. El relato chileno visto desde el exterior. Valparaíso: Puntángeles Universidad de Playa Ancha Editorial.

RíO, A. (1991). De golpe, Amalia en el umbral. Santiago de Chile: Andrés Bello. RIVAS, P. (2007). Chile, un largo septiembre. Santiago de Chile: LOM Ediciones. ROJAS, L. (2011). De la rebelión popular a la sublevación imaginada. Antecedentes de la historia politica y militar del Partido Comunista de Chile y del FPMR 19731990. Santiago de Chile: LOM Ediciones.

SIME, F. (2009). Carne de perra. Santiago de Chile: LOM Ediciones.

SKÁRMETA, A. (1982). La insurrección. Hanover: Ediciones del Norte.

Síntesis y evaluación de la experiencia guerrillera de Neltume y Nahuelbuta 19801981 (1985). Disponible en internet: http://chile-mir.net/archives/378

VERA, C. (2013). Hacia una narrativa de acción guerrillera en Chile. Santiago de Chile: Tesis para optar al grado de Magíster en Literatura Latinoamericana y Chilena, Universidad de Santiago de Chile. 